\title{
Processing and Characterization of High Density Polyethylene/Ethylene Vinyl Acetate Blends with Different VA Contents
}

\author{
Othman Y. Alothman \\ Chemical Engineering Department, King Saud University, P.O. Box 800, Riyadh 11421, Saudi Arabia \\ Correspondence should be addressed to Othman Y. Alothman, othman@ksu.edu.sa
}

Received 27 August 2012; Accepted 3 November 2012

Academic Editor: Zhennan Gu

Copyright ( $) 2012$ Othman Y. Alothman. This is an open access article distributed under the Creative Commons Attribution License, which permits unrestricted use, distribution, and reproduction in any medium, provided the original work is properly cited.

\begin{abstract}
Different series of high density Polyethylene/Ethylene Vinyl Acetate (HDPE/EVA) blends were prepared via melt blending in a corotating intermeshing twin screw extruder. The effects of VA percentage and EVA loading ratio on the thermal, rheological viscoelastic, mechanical, and fracture toughness of the blends were analyzed. The results showed that the addition of EVA to HDPE reduces the thermal, elastic, and viscoelastic properties of the blends. The microscopic examination of the fracture surface confirmed the ductile fracture of HDPE/EVA blends for all blend ratios and VA percentages. Increasing the EVA ratio and VA content caused a significant reduction in the blend crystallinity but had no significant effect on melting temperature. The complex viscosity increased with increasing the percentage of EVA due to the restriction of molecular mobility and reduction of free volume, induced by the addition of EVA. The storage modulus decreased with increasing the EVA ratio and temperature, while it increased with increasing the frequency. Young's modulus, yield strength, and fracture strain decreased with increasing the EVA ratio. Similarly, the fracture toughness decreased proportional to the EVA percentage. Finally the results indicated that the VA content has significant effects on the mechanical, thermal, and dynamic properties of HDPE/EVA blends.
\end{abstract}

\section{Introduction}

Polyethylene (PE) is being increasingly used in many industrial and biomedical applications. Its outstanding features such as regular chain structure, combination of low cost and low energy demand for processing, excellent biocompatibility, and good mechanical properties make PE expand its application continuously [1-5]. The superiority of PE products over metal products is attributed to their light weight, high corrosion resistance, and low costs. However, there are some drawbacks with Polyethylene including low environmental stress cracking resistance, low creep resistance, and poor compatibility with various additives which restricted its use for cretin purposes [6, 7]. Therefore, there have been many attempts to improve the properties of polyethylene by blending it with organic or inorganic materials [6-14].
Among these materials is Ethylene Vinyl Acetate (EVA) copolymer, a member of the polyolefin family derived from random copolymerization of Vinyl Acetate (VA) and Ethylene. EVA properties vary substantially as a function of VA content [5]. The VA content has two main effects on polyethylene (PE). First, increasing VA content decreases the crystallinity of PE. Although PE crystallinity could reach $65 \%$, EVA with about $50 \mathrm{wt} \%$ VA is completely amorphous. Second, the polarity of EVA increases as VA content increases as a result of the polar nature of the acetoxy side chain. This permits manipulating important properties to suit diverse applications, including flexible shrink wrap, agricultural films, coatings, paints, footwear soles, hot melt and heat seal adhesives, semipermeable film, flexible toys and tubing, and crosslinked foamed tires [6].

The addition of EVA to PE can improve its transparency, flexibility, thermal resistivity, environmental stress cracking 
resistance, electrical resistance, and higher loading capacity of fillers [15-23]. In addition, the blends of PE/EVA possess high thermo shrinkage and high stability when subjected to aging, weathering, and aggressive media [24]. Therefore, the $\mathrm{PE} / \mathrm{EVA}$ blends are used in many applications including high voltage cable systems, multilayer packaging films and sheets, automobile parts, agricultural films, medical tubes, and so on.

There is a great body of publications that deal with the fabrication and characterization of PE/EVA blends. Among these are Facker et al. [23] who studied the rheology, morphology, and mechanical properties of binary PE and EVA blends. Akhlaghi et al. [26] investigated the effects of a phosphate containing stabilizer on the mechanical, morphological, and thermal properties of HDPE/EVA blends containing an ammonium quaternary salts modified montmorillonite.

This study is a part of a research project, aiming to investigate the effects of VA content and blending ratio of $\mathrm{PE} / \mathrm{EVA}$ on the overall thermal, elastic, viscoelastic, and fracture toughness for PE/EVA blends. Applications of such blends may include children toys, medical tubes and pipes, household gloves, picnic mats, slippers, and so on.

\section{Experimental Work}

2.1. Material. The polyolefin used in the present work was an injection molding grade of high density polyethylene (HDPE) from the local market in Saudi Arabia. Its melt flow index is of $30 \mathrm{~g} / 10 \mathrm{~min}$

Two grades of Ethylene Vinyl Acetate with different VA content were used. The first EVA grade contains $27 \mathrm{wt} \%$ VA (Escorene Ultra FL 00328) with melt index of $3 \mathrm{~g} / 10 \mathrm{~min}$, referred to as EVA328. The second grade contains $6.5 \mathrm{wt} \% \mathrm{VA}$, (Escorene Ultra FL 00206) with melt index of $2.5 \mathrm{~g} / 10 \mathrm{~min}$, referred to as EVA206. The EVA was supplied by ExxonMobil Chemicals, Belgium.

Blends of HDPE and different grades of EVA were prepared at HDPE/EVA weight ratios of 100/0, 95/5, 80/20, and $60 / 40$ by using a co-rotating intermeshing twin screw extruder (Farrel Limited, FTX 20, UK), a diameter of $26 \mathrm{~mm}$, and an $L / D=35$. The processing conditions were $200^{\circ} \mathrm{C}$ and 24 RPM. The extruded strings were cooled in a water bath at about $12^{\circ} \mathrm{C}$, air-dried, and then palletized into granules. The granules were further dried and conditioned in the lab environment for 40 hours. The granules were then injection molded to obtain a set of standard ASTM D638 type I specimens [27]. The injection molding temperature was about $220^{\circ} \mathrm{C}$ and the total cycle time was 35 seconds. Specimens were conditioned in a standard lab environment for 40 hours before further testing.

2.2. Characterization Methods. The fracture surfaces of HDPE/EVA specimens were examined using Scanning Electron Microscope (SEM Model JSM 6360A, Jeol Company, Japan). The specimens were fixed with double coated carbon tape which was also used for dissipation of the electron beam charge and heat buildup. All the specimens were coated with a thin layer of Gold under vacuum prior to SEM observation, using an IFC 1600 coating machine. The main aim of fractographic examination was to investigate the effects of EVA content on the blend fracture.

Differential Scanning Calorimetry (DSC) tests were performed on DSC-6 series (Schimadzu, Japan) with samples of $\approx 5 \mathrm{mg}$ sealed in an aluminum pan. Each specimen was placed in the DSC oven and heated at a rate of $5^{\circ} \mathrm{C} / \mathrm{min}$ to $200^{\circ} \mathrm{C}$. The heat of melting was calculated by integrating the area under the DSC endothermic peak of the DSC thermogram. The melting temperature was taken at the peak of the melting process. The percentage crystallinity was calculated by normalizing the heat of melting to that of $100 \%$ crystalline PE $(290 \mathrm{~J} / \mathrm{g})$, by the following equation $[4,28]$ :

$$
X_{c}=\frac{\Delta H_{m}}{\Delta H_{m}^{+}},
$$

where $X_{c}$ is the degree of crystallinity, $\Delta H_{m}$ is the specific enthalpy of melting, and $\Delta H_{m}^{+}$is the specific enthalpy of melting for $100 \%$ crystalline PE.

The rheological and viscoelastic properties of the PE/EVA blends were characterized using a Dynamic Mechanical Analysis, DMA, (AR-G2 from TA, USA). The rheological properties were measured via a plate-plate geometry that had $25 \mathrm{~mm}$ plate diameter, and a gap of $1.0 \mathrm{~mm}$. The samples were heated to $190^{\circ} \mathrm{C}$, stabilized at this temperature for 5 minutes. The specimens were tested over a frequency range from 0.01 to $600 \mathrm{rad} / \mathrm{sec}$. The viscoelastic properties were measured under torsion arrangement by heating and stabilizing the samples at $90^{\circ} \mathrm{C}$ for 5 minutes, and then a frequency sweep test from 0.1 to $600 \mathrm{rad} / \mathrm{sec}$ was performed.

The tensile test up to fracture was performed at room temperature at a displacement rate of $20 \mathrm{~mm} / \mathrm{min}$ At least three specimens were tested at each condition and the standard deviation was determined. The engineering yield strength was determined from the upper stress point, and Young's modulus was calculated from the initial linear region of the stress strain. The engineering and true stress strain curves were calculated using standard methods [28] as follows:

$$
\begin{gathered}
\sigma_{N}=\frac{F}{A_{o}}, \\
\varepsilon_{N}=\frac{L-L_{o}}{L_{o}} .
\end{gathered}
$$

The fracture toughness $\left(K_{I}\right)$ was calculated from a single edge notch (SEN) specimens tested under tension at $500 \mathrm{~mm} / \mathrm{min}$ The SEN specimen had a sharp crack that was $10 \%$ of the sample width. The fracture toughness was calculated using, [29],

$$
K_{I}=\sigma \cdot \sqrt{Y^{2} \cdot a},
$$

where $\sigma$ is the fracture stress, $Y^{2}$ is a correction factor equals to 4.42 for SEN samples, and $a$ is the crack length.

The Rockwell hardness of the HDPE/EVA blends was calculated from Leeb rebound test. Leeb test is a typical rebound hardness test where the energy of an indenter before and after an impact is calculated. Hence, the hardness of the material could be determined. 
EVA206
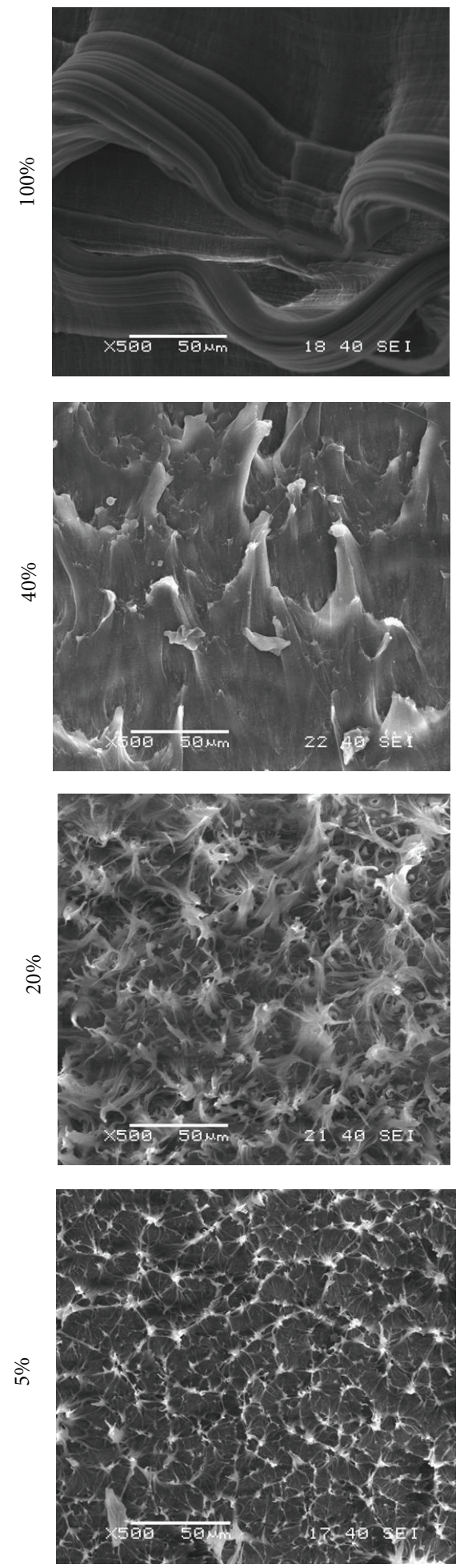

EVA328
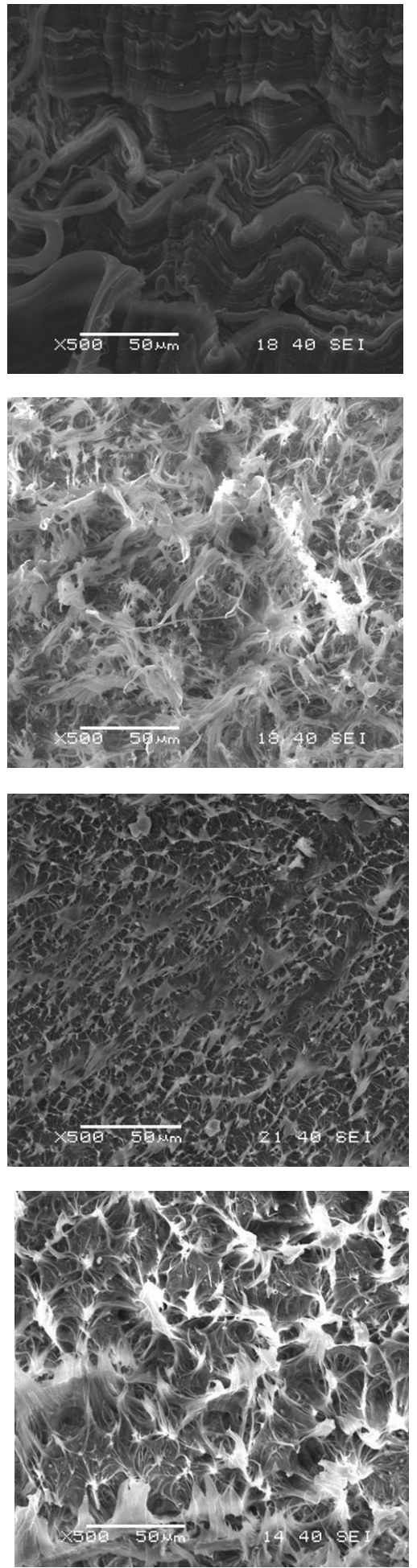

Figure 1: Fracture surface of HDPE/EVA (40\%).

\section{Results and Discussion}

3.1. Fracture Surface. The SEM images for the fracture surface of HDPE/EVA206 and HDPE/EVA328 specimens are shown in Figure 1. They show the presence of fibrous surface at the specimen fracture surface.

During tensile tests of HDPE/EVA blends, a stress whitening zone develops throughout the length of the neck 


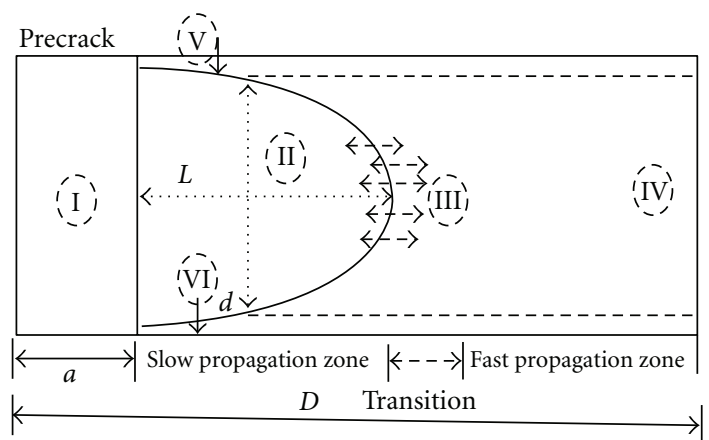

FIGURE 2: Schematic representation of fracture surface of HDPE or composite with a precrack (with permission of authors of [25]).

which can be attributed to the various processes that can take place in the polymer, such as matrix crazing, matrix shear yielding, and so forth. The fractured micrograph images of the HDPE and EVA blends display interplay of multiple voiding and matrix fibrillation. The fibril length of HDPE was longer than that of the blends which is an indication of high stress concentration level of the blends.

Microscopic investigation of the fracture surfaces of neat HDPE and the blend samples with a precrack revealed a completely different morphology and fracture mechanism than that of the tensile sample. Ali and Elleithy [25] proposed a precracked fracture mechanism as illustrated in Figure 2. The surface of a fractured sample with a precrack can be divided into three main zones: I, initial precrack zone; II, slow crack propagation zone; and IV, fast crack propagation zone. In addition, the crack propagation zone could be further subdivided into three zones, namely, transition zone III (slow-to-fast propagation zone) and two skin zones $\mathrm{V}$ and VI. The slow crack propagation zone (II) has an elliptical shape that could be characterized by its length (L) and width (d) [25].

SEM images clearly reveal that these samples have two distinctive crack propagation zones: slow crack and fast crack propagation zones. The lengths of these zones have been affected by the percentage of EVA concentration. It is observed that the slow crack propagation zone length increases with increasing the EVA content for both EVA grades. The matrix fibrillation was thick and short for blends containing less percentage of EVA as compared to those with high percentage of EVA. As the EVA content increases the fibrils become thinner and longer.

The EVA grade also affects the mechanism of sample fracture. The EVA 328 contains higher level of vinyl acetate (VA) than the EVA206. It is evident that the matrix fibrils were thinner and longer in HDPE/EVA328 samples than those of HDPE/EVA206. This may be attributed to the higher VA content in EVA328 blends.

The uniform fiber pullout shown in the fracture surface at the specimen circumference is an indicator of ductility for all blends with different EVA loading ratio and VA percentage.

3.2. Thermal Properties. The DSC heating curves of blends are presented in Figures 3 and 4, respectively. Figure 3(a)
TABLE 1: Melting temperature and crystallinity percentage of HDPE/EVA blends.

\begin{tabular}{lcccc}
\hline \multirow{2}{*}{ EVA content \% } & \multicolumn{2}{c}{ Melting temp. $\left({ }^{\circ} \mathrm{C}\right)$} & \multicolumn{2}{c}{ Crystallinity \% } \\
& EVA206 & EVA328 & EVA206 & EVA328 \\
\hline 0 & 131 & 131 & 58 & 58 \\
5 & 131 & 130 & 43 & 45 \\
20 & 129 & 129 & 48 & 42 \\
40 & 130 & 129 & 37 & 33 \\
100 & 100 & 72 & 21 & 6 \\
\hline
\end{tabular}

shows the DSC results of the first heat for HDPE, EVA206, and their blends while Figure 3(b) shows the DSC results for HDPE, EVA328, and their blends. Figure 3, shows single endothermic peaks for $\operatorname{HDPE}\left(T_{m}=131^{\circ} \mathrm{C}\right)$, EVA206 $\left(T_{m}=100^{\circ} \mathrm{C}\right)$, and EVA328 $\left(T_{m}=72^{\circ} \mathrm{C}\right)$ representing the melting temperature of their crystalline phase. The results also indicated that as the VA content increased from $6.5 \%$ to $27 \%$ wt in the EVA copolymer, the EVA melting temperature peak decreases from 100 to $72^{\circ} \mathrm{C}$ and the associated enthalpy was also reduced from 72 to $12 \mathrm{~J} / \mathrm{g}$. Similar results have been reported by Khonakdar et al. [19] where the EVA crystallinity and the melting temperature decreased due to the increase in VA content.

The DSC results show that the melting temperature of HDPE/EVA blends slightly decreased due to the addition of EVA copolymer. This decrease of the melting temperature of HDPE/EVA crystalline phase to a lower temperature can be attributed to the dilution effects of EVA and/or due to cocrystallization of PE with part of EVA. The presence of single peak for all the blends near the HDPE melting temperature verify both good miscibility of EVA in the HDPE and high extent of cocrystallization in the blend composition with respect to EVA content [17, 19, 22, 23].

The crystallization of HDPE and HDPE/EVA blends was judged via the heat of fusion, $\Delta H$. As the heat of fusion increases, so does the crystallization. Figure 4 shows that the EVA and VA contents have no significant effects on the crystallization temperature of the blends, but they reduce the crystallinity of the blends. For example, the relative crystallinity of HDPE decreased from 58\% to $42 \%$ and $33 \%$ due to the addition of $20 \%$ and $40 \%$ EVA328, respectively. A comparison between the effects of EVA and VA contents in the HDPE/EVA blends crystallinity is shown in Table 1. The reduction in the crystallinity of HDPE/EVA328 blends is much more pronounced than that of HDPE/EVA206 because EVA206 has higher crystallinity than EVA328. Generally, in the HDPE/EVA blends, EVA dispersed phase has a distributing role in the arrangement of HDPE chain molecules in a crystal lattice when cooling from melt, resulting in reduction in the blend [23].

3.3. Rheological Behavior of HDPE/EVA Blends. The results of complex viscosity for HDPE and EVA as a function of angular frequency at $190^{\circ} \mathrm{C}$ are shown in Figure 5. These results show that the neat polymers exhibit a power-law flow behavior, with the viscosity order as EVA328 > EVA206 > HDPE in 


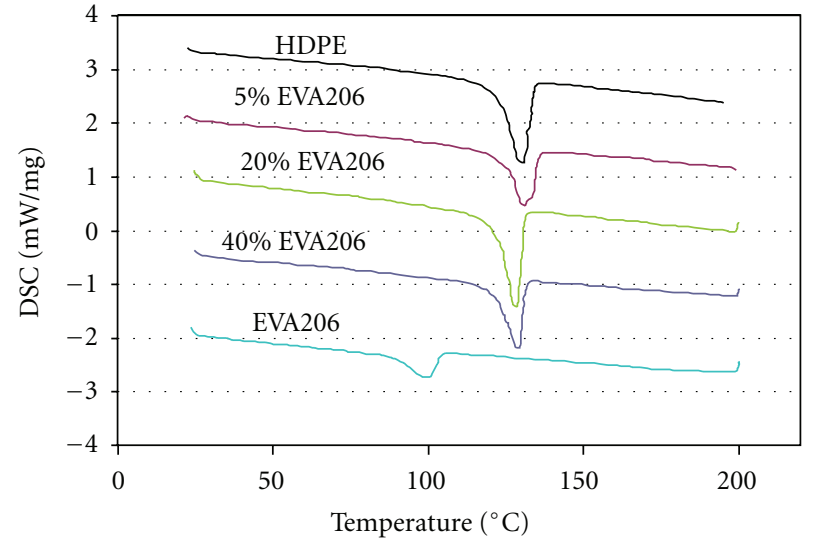

(a)

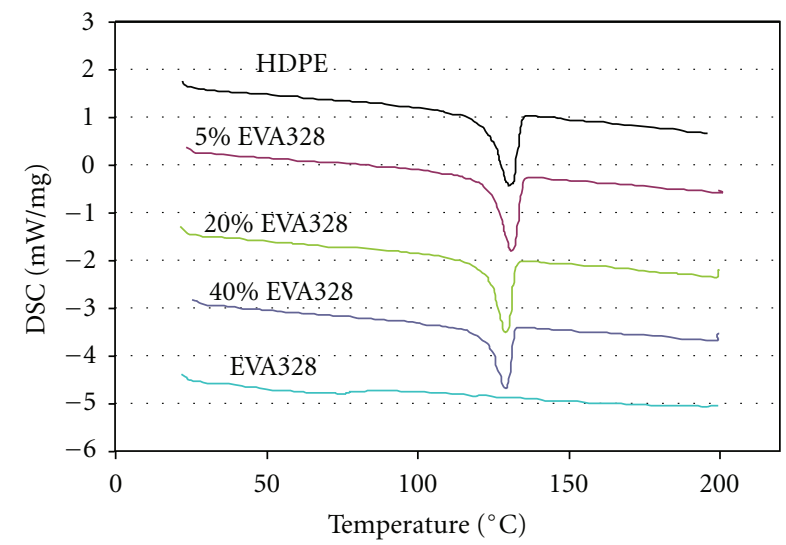

(b)

FIgure 3: (a) DSC thermal curves of HDPE, EVA206, and their blends. (b) DSC thermal curves of HDPE, EVA328, and their blends.

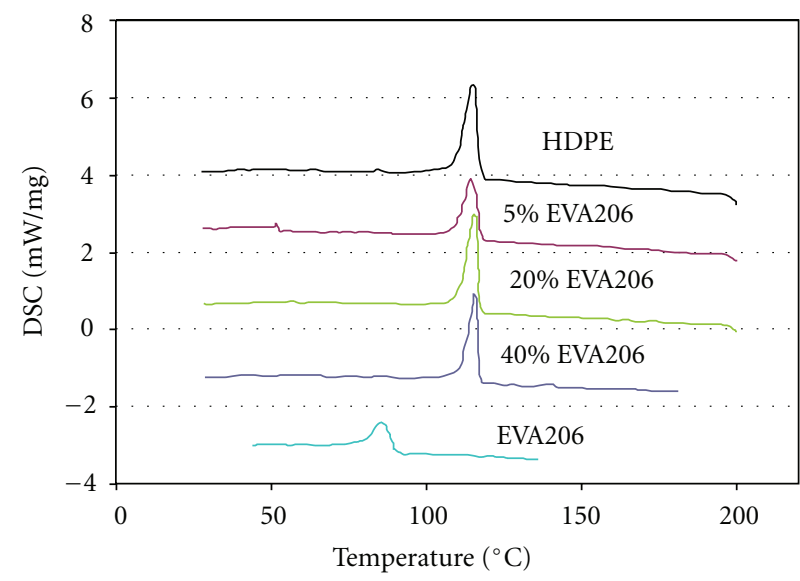

(a)

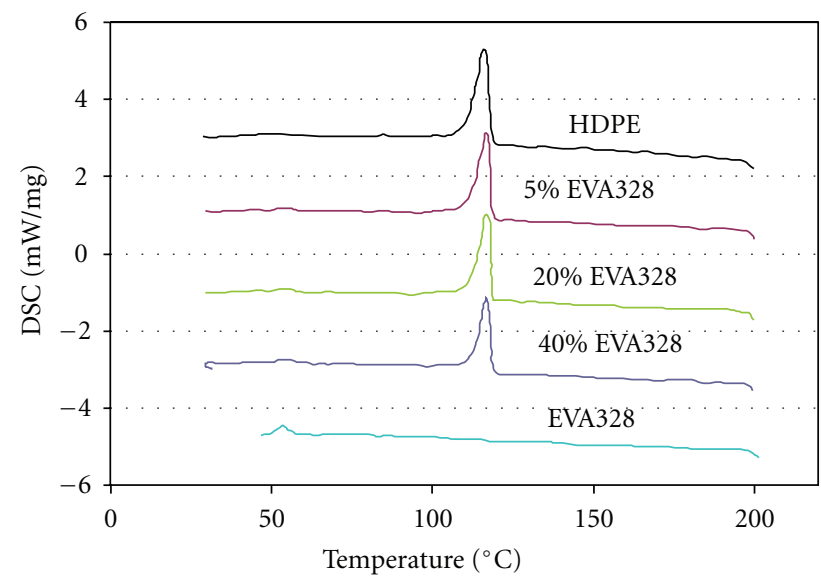

(b)

FIGURE 4: (a) DSC heat curves of HDPE, EVA206, and their blends. (b) DSC heat curves of HDPE, EVA328, and their blends.

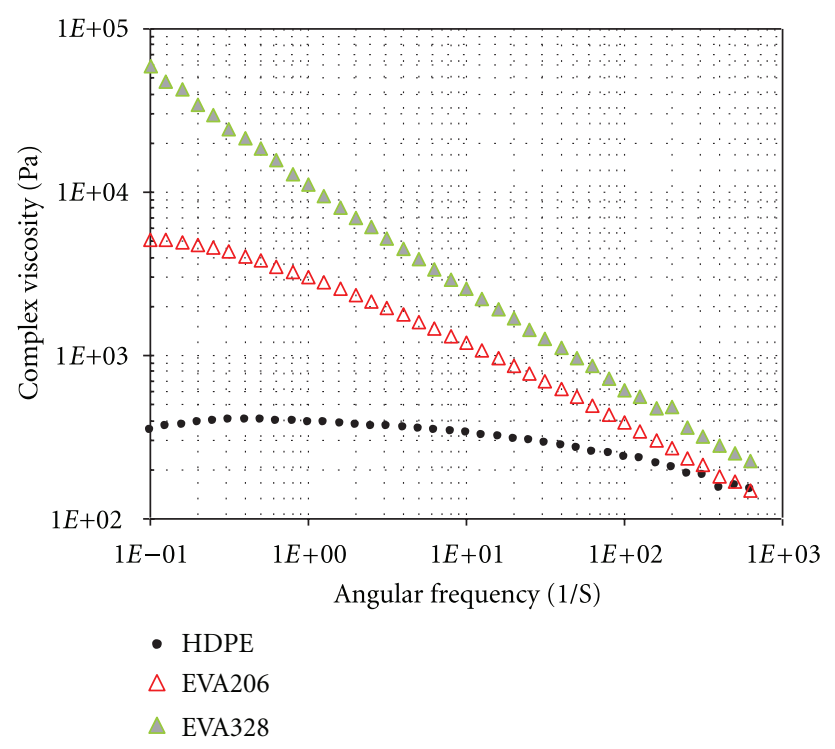

FIGURE 5: Complex viscosity of the pure materials. almost all frequency ranges. The higher viscosity of EVA328 could be due to its structural characteristics, such as molecular weight and branching. Molecular entanglements in branched polymers may contribute to a much more rapid increase in Newtonian viscosity than in unbranched polymers.

The relationship between the complex viscosity and the angular frequency at $190^{\circ} \mathrm{C}$ of HDPE/EVA206 and HDPE/ EVA328 blends are shown in Figure 6. The results show that the complex viscosity of the blends increases with increasing the EVA contents for both types of EVA especially at higher EVA loading ratios. Similar results have been obtained by Khonakdar et al. [22], where the complex viscosity of the polyethylene increased with increasing the EVA content. Also these results clearly indicate that all the blends behave as shear thinning materials and could be divided into two regions: (i) high shear thinning at lower frequencies, and (ii) low shear thinning at higher frequencies. It is observed that in some cases, the viscosities of the blends are less than those of their neat polymers especially at higher frequency 
TABLE 2: Rockwell hardness of neat HDPE and its blends.

\begin{tabular}{lccccc}
\hline Material & HDPE & HDPE/EVA206 (5\%) & HDPE/EVA206 (10\%) & HDPE/EVA206 (20\%) & HDPE/EVA206 (40\%) \\
\hline Calculated Rockwell & 41 & 38 & 37 & 35 & 33 \\
hardness & HDPE & HDPE/EVA328 (5\%) & HDPE/EVA328 (10\%) & HDPE/EVA328 (20\%) & HDPE/EVA328 (40\%) \\
& 41 & 35 & 33 & 28 & 27 \\
\hline
\end{tabular}

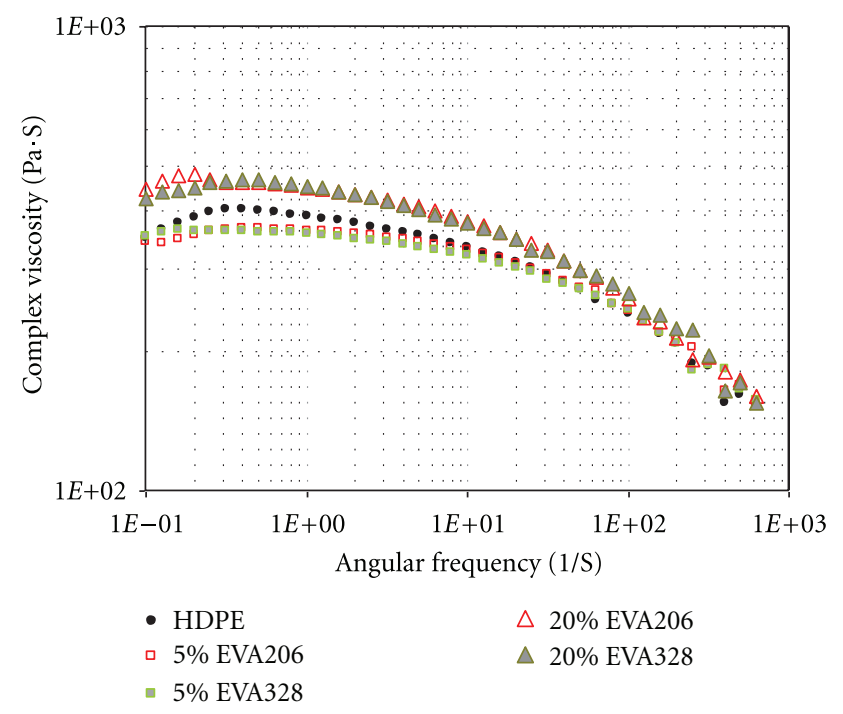

Figure 6: Complex viscosity at different ratios of HDPE/EVA206 and HDPE/EVA328.

range. As illustrated in Figure 6, no conclusive difference can be observed between the addition of the same quantities of EVA206 and EVA328. This could be due to the weak effect of completely dispersed molecules of EVA in the matrix of the polyethylene. Moreover, at rich EVA blends, the viscosities of the blends were higher than that of the neat resins. This is due to the restriction of the molecular mobility and the reduction of the free volume that were induced by the addition of EVA. Higher melt viscosity is an advantage in the melt spinning because it promotes faster hall off speeds [30]. On the other hand, a higher melt viscosity would lead to a higher load of the extruder motor which could be a disadvantage.

Figure 7 demonstrates the Cole-Cole plots for HDPE/ EVA blends. These curves appear to be linear. The linearity of Cole-Cole curves indicates homogeneity in morphology, and curves' spacing reflects independence of blending ratio and good compatibility [22].

3.4. Dynamic Mechanical Analysis. The response of storage modulus $\left(\mathrm{G}^{\prime}\right)$ to the testing frequency for HDPE, EVA and their blends is shown in Figures $8(\mathrm{a})$ and $8(\mathrm{~b})$. The neat EVA328 has the lowest storage modulus at all frequencies, whereas HDPE has the highest modulus. EVA has higher damping intensity than HDPE because of its rubbery nature [31]. As the percentage of EVA increases, the storage modulus decreases accordingly. For all the blends, $G^{\prime}$ increases with increasing the testing frequency which is a manifestation of the viscoelastic behavior (time dependent) of HDPE and its

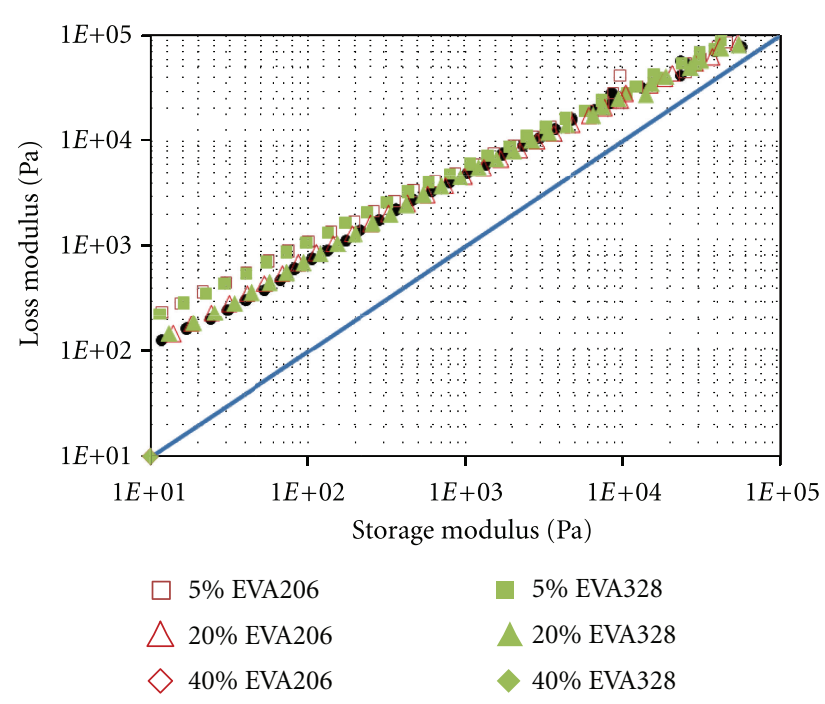

Figure 7: Cole-Cole diagram of HDPE/EVA blends.

blends. Additionally, the storage modulus of all HDPE/EVA blends decreases with increasing the EVA content. This phenomenon was also observed for the tensile strength which will be discussed in the next section. This decrease in the storage modulus can be attributed to the decrease of the blend crystallinity and the stiffness of the polymeric matrix, resulting from the increase in chain mobility and enhancement of free volume due to the presence of VA. The addition of EVA allows the control of the mechanical properties from stiff materials to a rubbery material. Moreover, the reduction in the storage modulus can be attributed to the presence of weak interfacial interaction between phases in the HDPE/EVA blend. The effect of temperature on the storage modulus of HDPE, EVA, and their blends is depicted in Figures 9(a) and 9(b). As the temperature increases, the neat HDPE modulus decreases due to the increase of the molecular chains mobility.

3.5. Mechanical Properties. Figures 10 to 12 show the variations of Young's modulus, stiffness, and yield strength for HDPE/EVA blends with different loading ratios of EVA. As shown in Figure 10, increasing the EVA content in the blend decreases the Young's modulus due to the decrease in crystallinity of the blends.

Figure 11 shows the percentage of modulus drop as indication of the stiffness decrease. The stiffness of the HDPE with $5 \%, 20 \%$, and $40 \%$ EVA206 decreases by $5 \%, 17 \%$, and $23 \%$, respectively, comparing to the neat HDPE. A similar observation was seen with the stiffness of the HDPE/EVA328 


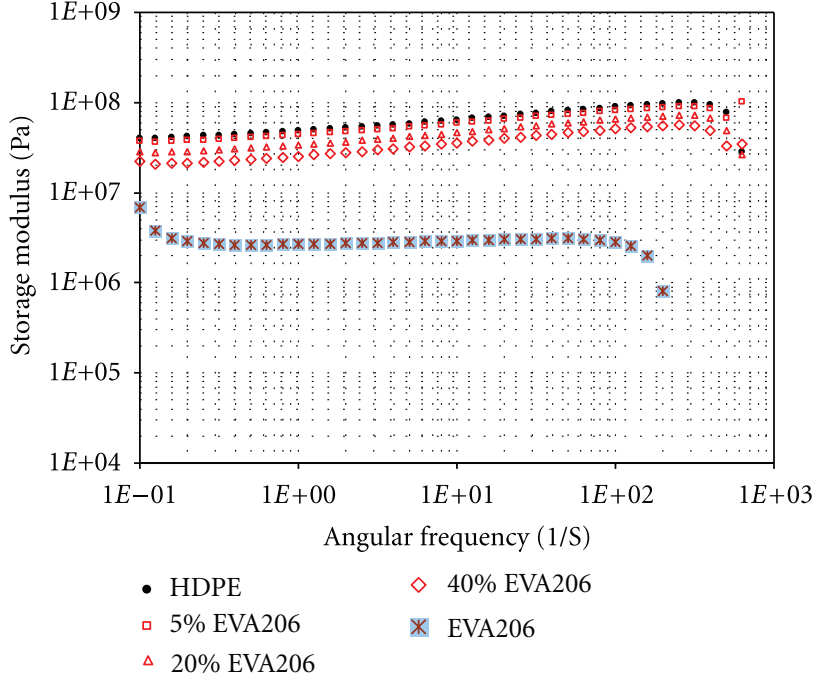

(a)

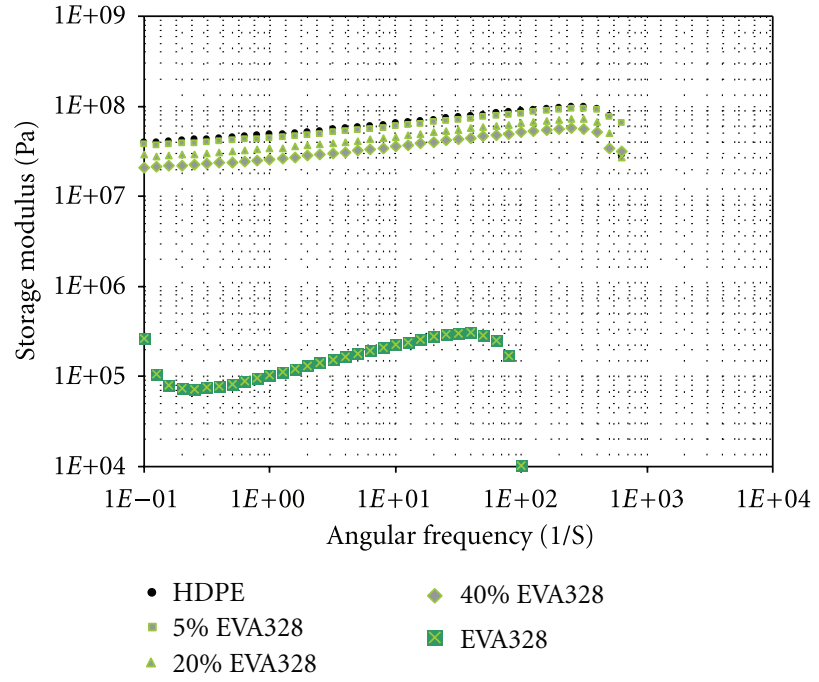

(b)

Figure 8: (a) Frequency sweep at $90^{\circ} \mathrm{C}$ for HDPE/EVA206 blends. (b) Frequency sweep at $90^{\circ} \mathrm{C}$ for HDPE/EVA328 blends.

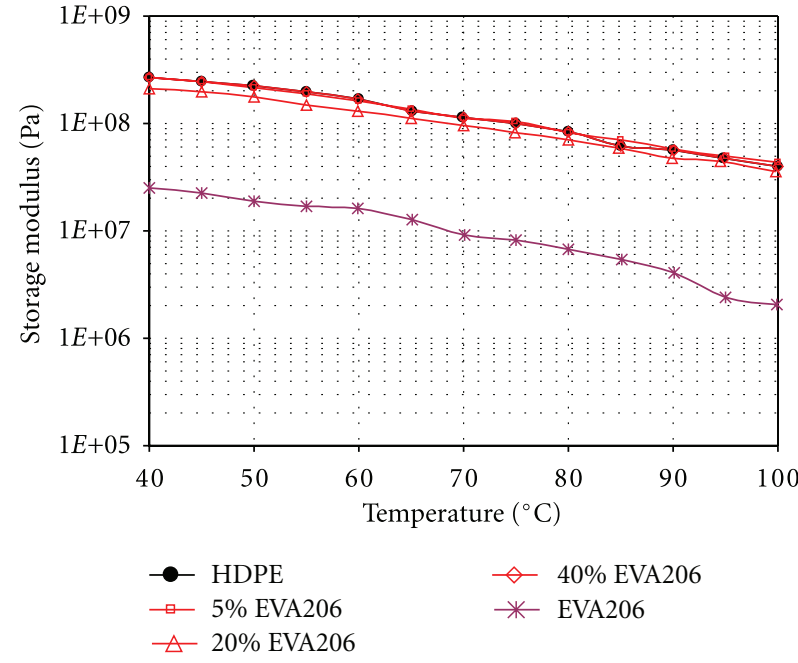

(a)

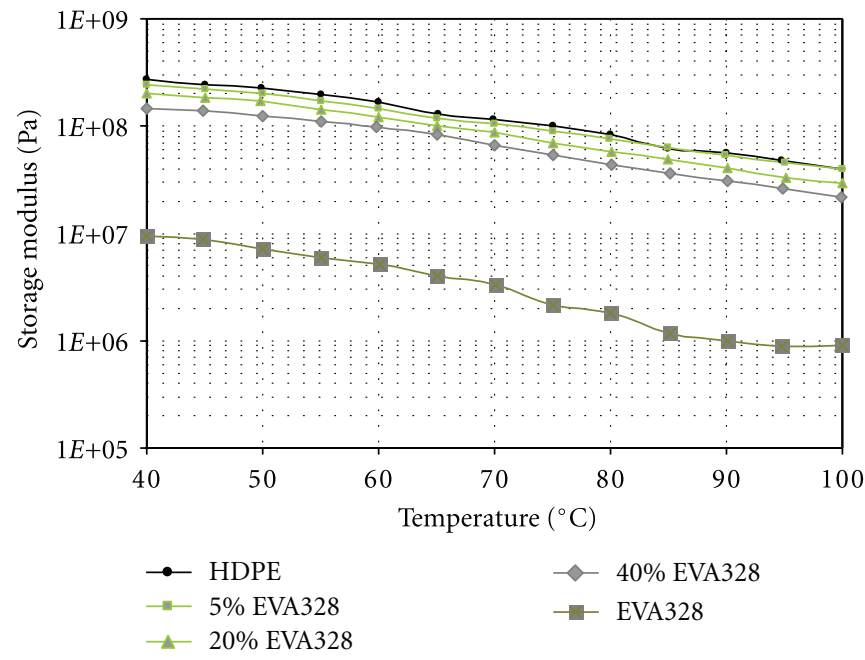

(b)

Figure 9: (a) Effect of temperature on the storage modulus of HDPE, EVA206, and their blends. (b) Effect of temperature on the storage modulus of HDPE, EVA328, and their blends.

blends. Moreover, Figure 11 shows that for the same blending ratio of HDPE/EVA206 and HDPE/EVA328 the stiffness of the blend decreases with increasing the VA content. For example, the modulus of HDPE with $40 \%$ EVA decreases by $7 \%$ when VA content in the EVA increases from $6 \%$ to $27 \%$, respectively.

Figure 12 shows that the yield strength of the HDPE/EVA blend decreases with increasing EVA content. The yield strength dropped to more than $40 \%$ for the HDPE blend with 40\% EVA328, comparing to the neat HDPE. Moreover, Figure 12 shows that the VA content has no significant effect on the yield stresses of the blends. Also, it is found that the HDPE/EVA blends exhibited typical cold drawing behavior before the final break of the specimens. This was manifested as a reduction of the elongation at break. The reduction on the stiffness and yield strength of HDPE/EVA blends can be attributed to the reduction on the blends crystallinity and to the possibility of presence of weak interfacial interaction between phases in the HDPE/EVA blends.

Therefore, the blend modulus, stiffness, and yield strength decrease with increasing the EVA content.

Figure 13 shows that the strain at fracture for the HDPE/EVA blends decreases with increasing the EVA content. For example, the strain at fracture of HDPE with $40 \%$ EVA328 decreases by about $50 \%$ than that of neat HDPE. Moreover, Figure 13 shows that the strain at fracture of the HDPE/EVA blends is nearly independent of the VA content in the EVA. The decrease in the strain at fracture with 


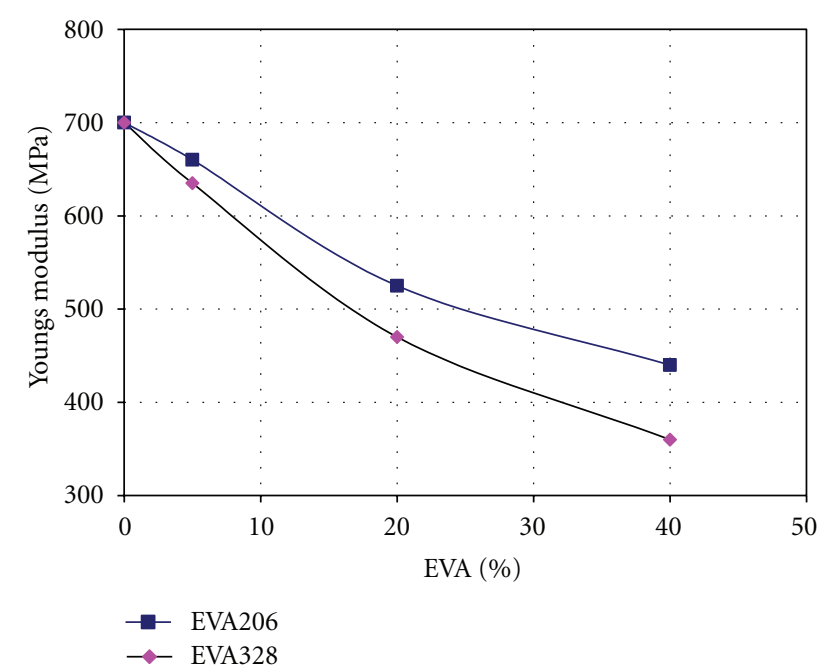

FIgURE 10: Variation of HDPE/EVA blends modulus with EVA contents and type.

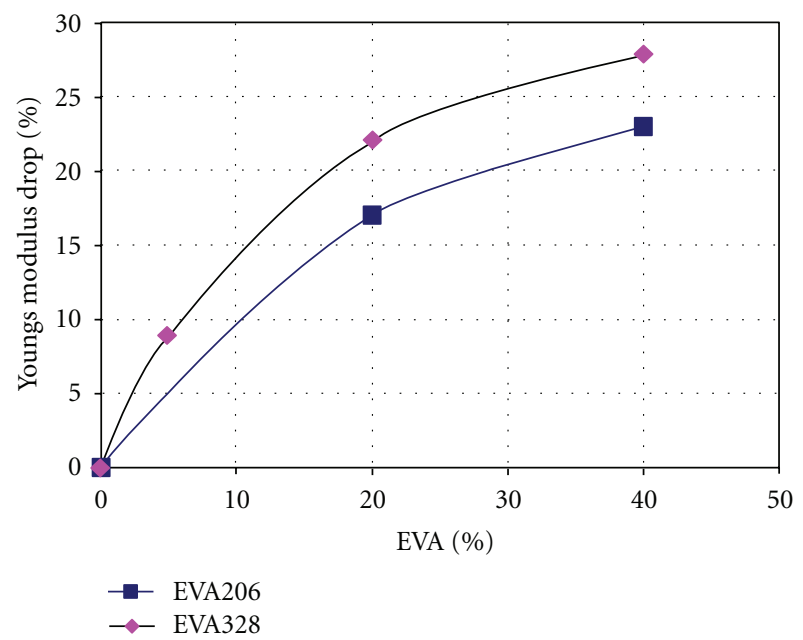

FIGURE 11: Storage modulus as a function of VA content.

increasing the EVA content may be caused by the changes in the morphology and the biphasic nature of the blends. Despite of the considerable reduction of the fracture strain of HDPE blends, it still is acceptable for many applications such as water cooling pipes and electric wire cables.

3.6. Fracture Toughness Measurements. The fracture toughness of HDPE and its blends was calculated according to (3). The fracture toughness $\left(K_{I}\right)$ of the blends was lower than that of the neat resin as seen in Figure 14. For example, $K_{I}$ of HDPE is about two times that of HDPE with 40\% EVA328. The presence of EVA in the HDPE reduces the ductility (as seen from the tensile properties) and reduces the fracture toughness as well.

3.7. The Rockwell Hardness. The hardness test provides a rapid evaluation of the variation on the mechanical properties due to the changes in chemical or processing

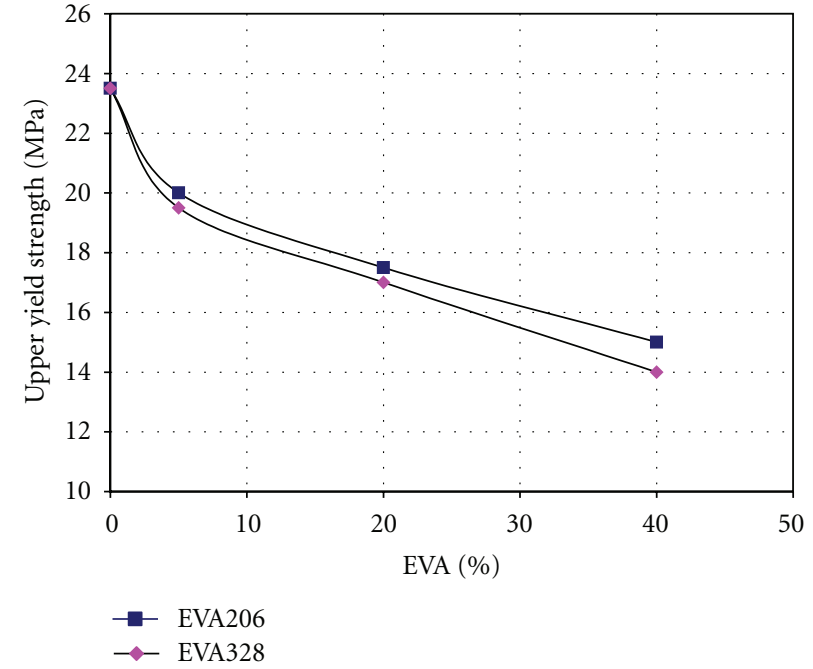

FIGURE 12: Variation of HDPE/EVA blends upper yield point with EVA contents and type.

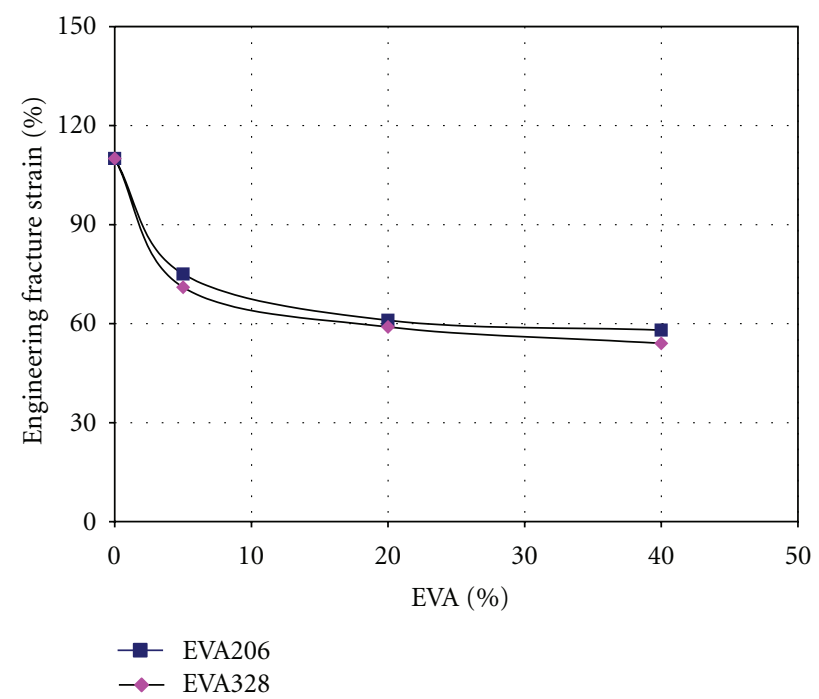

FIGURE 13: Variation of HDPE/EVA blends strain at fracture with EVA contents and type.

condition, heat treatment, microstructure, and aging. Also, the morphological and textural changes in the crystalline polymer can be detected by the hardness test. The Rockwell hardness results of the neat HDPE and its blends were calculated from Leeb rebound test and shown in Table 2. The results show that the material becomes softer as the EVA content increases which echoes the decrease in the blend properties. Moreover, the results indicate that with increasing the VA content in the EVA, the Rockwell hardness drops steadily and a more rubbery behavior can be observed. Also, the presence of a bulky group such as vinyl acetate (VA) in the EVA copolymer structure significantly reduces the crystallinity and gives a more rubber-like behavior to this copolymer, as compared with neat HDPE. Therefore, the reduction in the hardness and overall mechanical properties 


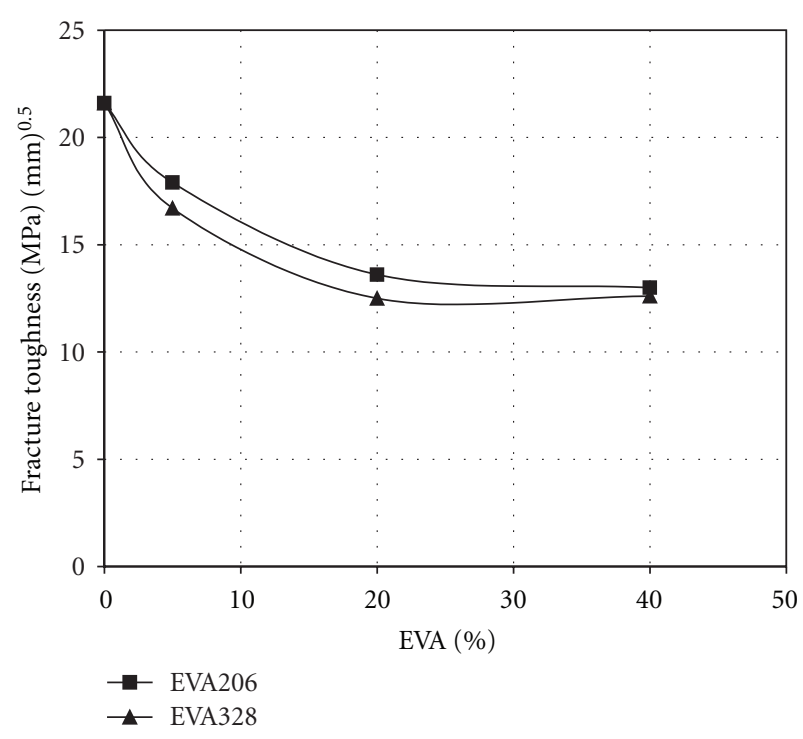

FIGURE 14: Variation of the fracture toughness of HDPE/EVA blends with EVA ratio.

can be attributed to the rubbery nature and low crystallinity of the EVA copolymer. Similar results have been obtained by many investigators, where the mechanical and viscoelastic properties and hardness decreased due to the addition of EVA and increase of VA contents [17, 19,22].

\section{Conclusion}

In the present study, HDPE/EVA206 and HDPE/EVA328 blends at various ratios were prepared using melt blending in a corotating intermeshing twin screw extruder. The microscopic examination of fractured surfaces confirmed the ductile fracture of HDPE/EVA for all EVA loading ratios of both grades. The thermal analysis results indicated that the EVA loadings significantly affect the crystallinity of the blends but not the melting temperature. The complex viscosity decreased with increasing the EVA percentage. This is due to the restriction of the molecular mobility and the reduction of the free volume. The storage modulus decreased with increasing the EVA ratio and testing temperature while increased with increasing the testing frequency. The tensile test results showed that Young's modulus, yield strength, and fracture strain decreased with increasing the EVA ratio. Finally the blend hardness and fracture toughness decreased with increasing the EVA content. This was attributed to the decrease of the crystallinity of the blends. In conclusion, the results indicated that the VA percentage has significant effects on the mechanical, thermal, and dynamic properties of HDPE/EVA blends.

\section{Acknowledgment}

The author would like to thank the Research Center of College of Engineering, at King Saud University, for supporting this work. Special thanks to Prof. Hasan Fouad and Dr. Ilias Ali for their valuable discussion and comments.

\section{References}

[1] K. Chrissafis, K. M. Paraskevopoulos, I. Tsiaoussis, and D. Bikiaris, "Comparative study of the effect of different nanoparticles on the mechanical properties, permeability, and thermal degradation mechanism of HDPE," Journal of Applied Polymer Science, vol. 114, no. 3, pp. 1606-1618, 2009.

[2] G. Sui, W. H. Zhong, X. Ren, X. Q. Wang, and X. P. Yang, "Structure, mechanical properties and friction behavior of UHMWPE/HDPE/carbon nanofibers," Materials Chemistry and Physics, vol. 115, no. 1, pp. 404-412, 2009.

[3] Y. Xue, W. Wu, O. Jacobs, and B. Schädel, "Tribological behaviour of UHMWPE/HDPE blends reinforced with multiwall carbon nanotubes," Polymer Testing, vol. 25, no. 2, pp. 221-229, 2006.

[4] A. H. I. Mourad, H. Fouad, and R. Elleithy, "Impact of some environmental conditions on the tensile, creep-recovery, relaxation, melting and crystallinity behaviour of UHMWPEGUR 410-medical grade," Materials and Design, vol. 30, no. 10, pp. 4112-4119, 2009.

[5] M. Kontopoulou and L. C. Huang, "Rheology, structure, and properties of ethylene-vinyl acetate/metallocene- catalyzed ethylene- $\alpha$-olefin copolymer blends," Journal of Applied Polymer Science, vol. 94, no. 3, pp. 881-889, 2004.

[6] A. M. Henderson, "Ethylene-vinyl acetate (EVA) copolymers: a general review," IEEE Electrical Insulation Magazine, vol. 9, no. 1, p. 30, 1993.

[7] A. Sharif, N. Mohammadi, and S. R. Ghaffarian, "Practical work of crack growth and environmental stress cracking resistance of semicrystalline polymers," Journal of Applied Polymer Science, vol. 110, no. 5, pp. 2756-2762, 2008.

[8] Q. Dong, Q. Zheng, M. Du, and M. Zhang, “Temperaturedependence of dynamic rheological properties for highdensity polyethylene filled with graphite," Journal of Materials Science, vol. 40, no. 13, pp. 3539-3541, 2005.

[9] Y. C. Li and G. H. Chen, "HDPE/expanded graphite nanocomposites prepared via masterbatch process," Polymer Engineering and Science, vol. 47, no. 6, pp. 882-888, 2007.

[10] W. Zheng, X. Lu, and S. C. Wong, "Electrical and mechanical properties of expanded graphite-reinforced high-density polyethylene," Journal of Applied Polymer Science, vol. 91, no. 5, pp. 2781-2788, 2004.

[11] S. Huang, K. Zhou, W. Zhu, B. Huang, and Z. Li, "Effects of in situ biomineralization on microstructural and mechanical properties of hydroxyapatite/polyethylene composites," Journal of Applied Polymer Science, vol. 101, no. 3, pp. 1842-1847, 2006.

[12] C. Sun, W. Zhao, and S. Chen, "Studies on the comprehensive performance of graphite and additives filled high density polyethylene composites," Journal of Applied Polymer Science, vol. 107, no. 6, pp. 4000-4004, 2008.

[13] N. Chen, L. Ma, and T. Zhang, "Investigation of nano-talc as a filling material and a reinforcing agent in high density polyethylene (HDPE)," Rare Metals, vol. 25, no. 6, pp. 422425, 2006.

[14] Y. Wang, J. Shi, L. Han, and F. Xiang, "Crystallization and mechanical properties of T-ZnOw/HDPE composites," Materials Science and Engineering A, vol. 501, no. 1-2, pp. 220228, 2009 .

[15] A. Behradfar, A. Shojaei, and N. Sheikh, "Rheological and mechanical characteristics of low density polyethylene/ ethylene-vinyl acetate/organoclay nanocomposites," Polymer Engineering and Science, vol. 50, no. 7, pp. 1315-1325, 2010. 
[16] C. Li, Q. Kong, J. Zhao, D. Zhao, Q. Fan, and Y. Xia, "Crystallization of partially miscible linear low-density polyethylene/poly(ethylene-co-vinylacetate) blends," Materials Letters, vol. 58, no. 27-28, pp. 3613-3617, 2004.

[17] I. L. Hosier, A. S. Vaughan, and S. G. Swingler, "An investigation of the potential of ethylene vinyl acetate/polyethylene blends for use in recyclable high voltage cable insulation systems," Journal of Materials Science, vol. 45, no. 10, pp. 2747 2759, 2010.

[18] H. A. Youssef, M. M. Senna, and H. M. Eyssa, "Characterization of LDPE and LDPE/EVA blends crosslinked by electron beam irradiation and foamed with chemical foaming agent," Journal of Polymer Research, vol. 14, no. 5, pp. 351-357, 2007.

[19] H. A. Khonakdar, S. H. Jafari, A. Haghighi-Asl, U. Wagenknecht, L. Häussler, and U. Reuter, "Thermal and mechanical properties of uncrosslinked and chemically crosslinked polyethylene/ethylene vinyl acetate copolymer blends," Journal of Applied Polymer Science, vol. 103, no. 5, pp. 3261-3270, 2007.

[20] X. Shi, J. Jin, S. Chen, and J. Zhang, "Multiple melting and partial miscibility of ethylene-vinyl acetate copolymer/low density polyethylene blends," Journal of Applied Polymer Science, vol. 113, no. 5, pp. 2863-2871, 2009.

[21] J. Jin, S. J. Chen, and J. Zhang, "Non-isothermal crystallization kinetics of partially miscible ethylene-vinyl acetate copolymer/low density polyethylene blends," Express Polymer Letters, vol. 4, no. 3, pp. 141-152, 2010.

[22] H. A. Khonakdar, S. H. Jafari, A. Yavari, A. Asadinezhad, and U. Wagenknecht, "Rheology, morphology and estimation of interfacial tension of LDPE/EVA and HDPE/EVA blends," Polymer Bulletin, vol. 54, no. 1-2, pp. 75-84, 2005.

[23] M. Faker, M. K. Razavi Aghjeh, M. Ghaffari, and S. A. Seyyedi, "Rheology, morphology and mechanical properties of polyethylene/ethylene vinyl acetate copolymer (PE/EVA) blends," European Polymer Journal, vol. 44, no. 6, pp. 1834$1842,2008$.

[24] A. Yamanaka, Y. Izumi, T. Kitagawa et al., "The radiation effect on thermal conductivity of high strength ultra-highmolecular-weight polyethylene fiber by $\gamma$-Rays," Journal of Applied Polymer Science, vol. 101, no. 4, pp. 2619-2626, 2006.

[25] I. Ali and R. Elleithy, "Toughness of $\mathrm{HDPE} / \mathrm{CaCO}_{3}$ microcomposites prepared from masterbatch by melt blend method," Journal of Applied Polymer Science, vol. 122, pp. 3303-3315, 2011.

[26] S. Akhlaghi, A. Sharif, M. Kalaee et al., "Effect of stabilizer on the mechanical, morphological and thermal properties of compatibilized high density polyethylene/ethylene vinyl acetate copolymer/organoclay nanocomposites," Materials and Design, vol. 33, pp. 273-283, 2012.

[27] ASTM D638-98, Standard Test Method for Tensile Properties of Plastics, vol. 8, Annual Book of ASTM Standards, Philadelphia, Pa, USA, 1999.

[28] H. Fouad, "Experimental and numerical studies of the notch strengthening behaviour of semi-crystalline ultra-high molecular weight polyethylene," Materials and Design, vol. 31, no. 3, pp. 1117-1129, 2010.

[29] J. G. Williams, Fracture Mechanics of Polymers, Ellis Horwood, Chichester, UK, 1987.

[30] H. Fouad, R. Elleithy, S. M. Al-Zahrani, and M. A. H. Ali, "Characterization and processing of High Density Polyethylene/carbon nano-composites," Materials and Design, vol. 32, no. 4, pp. 1974-1980, 2011.
[31] B. John, K. T. Varughese, Z. Oommen, P. Pötschke, and S. Thomas, "Dynamic mechanical behavior of high-density polyethylene/ethylene vinyl acetate copolymer blends: the effects of the blend ratio, reactive compatibilization, and dynamic vulcanization," Journal of Applied Polymer Science, vol. 87, no. 13, pp. 2083-2099, 2003. 

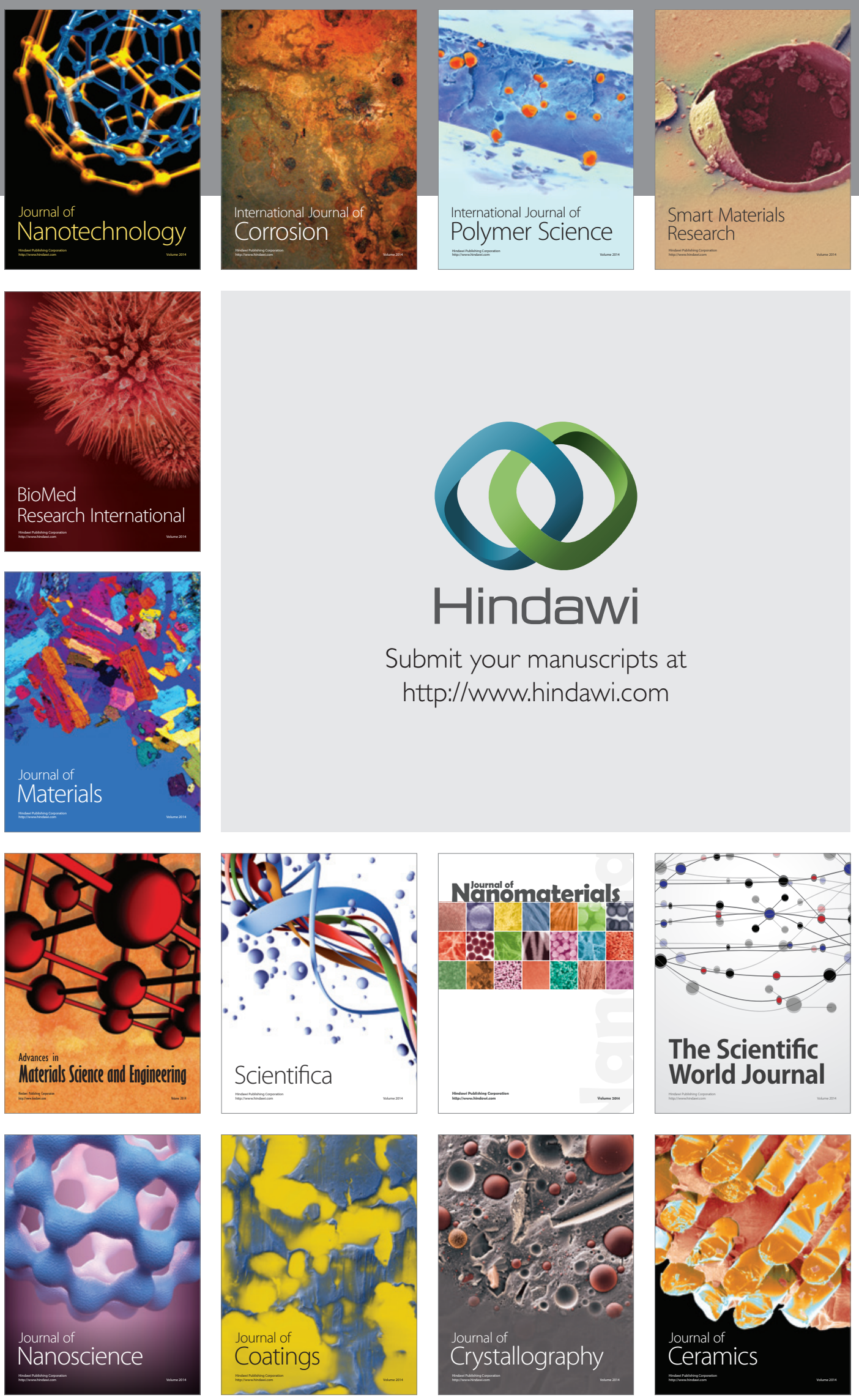

The Scientific World Journal

Submit your manuscripts at

http://www.hindawi.com

\section{World Journal}

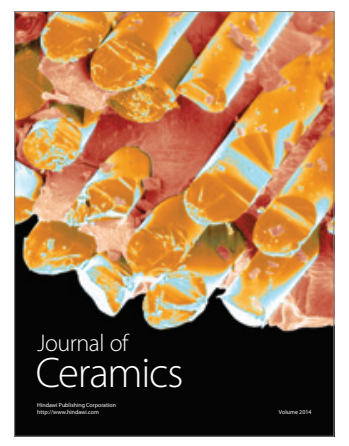

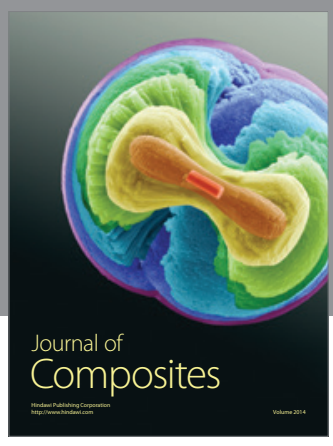
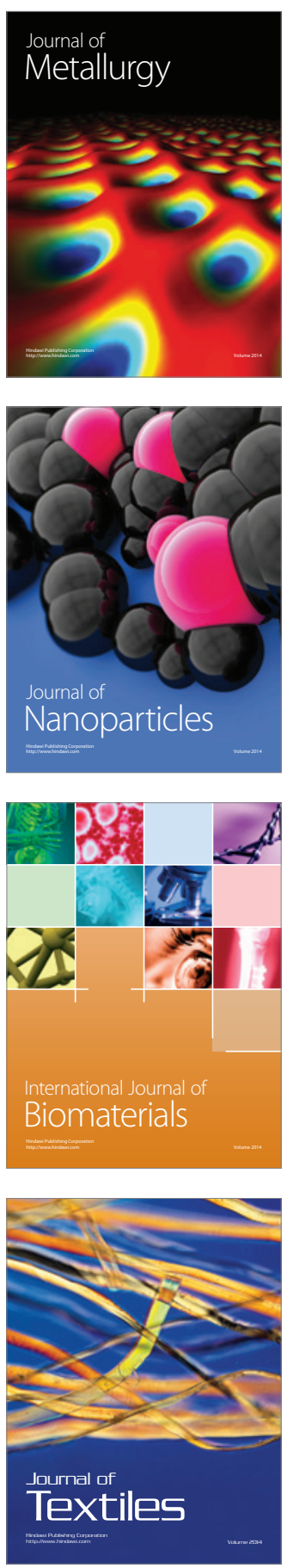